\title{
Light effects on the isotopic fractionation of skeletal oxygen and carbon in the cultured zooxanthellate coral, Acropora: implications for coral-growth rates
}

\author{
A. Juillet-Leclerc ${ }^{1}$ and S. Reynaud ${ }^{2}$ \\ ${ }^{1}$ LSCE Domaine du CNRS, 91198 Gif sur Yvette, France \\ ${ }^{2}$ CSM Avenue Saint-Martin, 98000 Monaco, Principality of Monaco
}

Received: 25 September 2009 - Published in Biogeosciences Discuss.: 3 November 2009

Revised: 18 February 2010 - Accepted: 26 February 2010 - Published: 8 March 2010

\begin{abstract}
Skeletal isotopic and metabolic measurements of the branching coral Acropora cultured in constant conditions and subjected to two light intensities were revisited. We individually compared the data recorded at low light (LL) and high light (HL) for 24 colonies, all derived from the same parent colony. Metabolic and isotopic responses to the different light levels were highly variable. High light led to productivity enhancement, reduction of surface extension, doubling of aragonite deposited weight and increased $\delta^{18} \mathrm{O}$ levels in all nubbins; responses in respiration and $\delta^{13} \mathrm{C}$ were not clear. The partitioning of the colonies cultured at HL into two groups, one showing a $\delta^{13} \mathrm{C}$ enrichment and the other a $\delta^{13} \mathrm{C}$ decrease revealed common behaviors. Samples showing an increase in $\delta^{13} \mathrm{C}$ were associated with the co-variation of low surface extension and high productivity while samples showing a decrease in $\delta^{13} \mathrm{C}$ were associated with the co-variation of higher surface extension and limited productivity.

This experiment, which allowed for the separation of temperature and light effects on the coral, highlighted the significant light influences on both skeletal $\delta^{18} \mathrm{O}$ and $\delta^{13} \mathrm{C}$. The high scattering of inter-colony $\delta^{18} \mathrm{O}$ observed at one site could be due to the differing photosynthetic responses of symbiotic algal assemblages.

We compared our results with observations by Gladfelter on Acropora cervicornis (1982). Both set of results highlight the relationships between coral-growth rates, microstructures and photosynthetic activity. It appears that extension growth and skeleton thickening are two separate growth
\end{abstract}

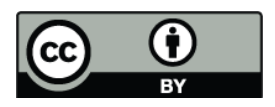

Correspondence to: A. Juillet-Leclerc (anne.juillet-leclerc@1sce.ipsl.fr) modes, and thickening is light-enhanced while extension is light-suppressed. There are multiple consequences of these findings for paleoclimatic reconstructions involving corals.

\section{Introduction}

As early as 1972, Weber and Woodhead demonstrated that the variability in oxygen-isotope compositions $\left(\delta^{18} \mathrm{O}\right)$ of scleractinian coral skeletons, although showing very negative values compared with the isotopic equilibrium, was essentially due to sea-surface temperature (SST), (Epstein et al., 1953). Correlations of SST with aragonite $\delta^{18} \mathrm{O}$ also differed among coral genera (Weber and Woodhead, 1972). Analysis of samples taken along the main growth axis of a coral head revealed that monthly $\delta^{18} \mathrm{O}$ signals were correlated with seasonal SST and seawater $\delta^{18} \mathrm{O}$ variations (Fairbanks and Dodge, 1979; McConnaughey, 1989a). Because it exhibited a strong seasonal signal such a sampling has been systematically used for paleoclimatic reconstructions of SST from coral $\delta^{18} \mathrm{O}$ measurements (e.g., Cole et al., 1993; Quinn et al., 1993; Dunbar et al., 1994). However, many heads of Porites lobata growing in close proximity at Clipperton Atoll showed isotopic discrepancies of up to $0.4 \%$ (Linsley et al., 1999), equivalent to a $2^{\circ} \mathrm{C}$ isotopic effect for the same period using the $\delta^{18} \mathrm{O} / \mathrm{SST}$ relationship estimated by Gagan et al. (1994). This discrepancy reached $1.28 \%$ (more than $6{ }^{\circ} \mathrm{C}$ ) for Porites spp. from the Gulf of Aqaba (Felis et al., 2003). It was concluded that ${ }^{18} \mathrm{O}$ concentrations were also colony dependent, this effect being commonly called the "vital effect" (Urey et al., 1951). Moreover, isotopic profiles may also change according to the axis sampled on a single coral

Published by Copernicus Publications on behalf of the European Geosciences Union. 
head (Maier et al., 2004). Such sources of variability could strongly compromise the validity of $\delta^{18} \mathrm{O}$ as an accurate environmental proxy.

Compared to the skeletal $\delta^{18} \mathrm{O}$ signature, interpretation of the variability of the carbon isotopic ratio $\left(\delta^{13} \mathrm{C}\right)$ within coral skeletons has long been a matter of debate. $\delta^{13} \mathrm{C}$ variability has therefore scarcely been considered for climatic reconstruction (Guzman and Tudhope, 1998). In contrast to $\delta^{18} \mathrm{O}$, which was assumed to essentially depend on external factors, $\delta^{13} \mathrm{C}$ has been generally considered as affected by coral physiology either via respiration rate (McConnaughey et al., 1997), or via the photosynthetic activity of the symbiotic zooxanthellae (Swart, 1983; McConnaughey, 1989a). Different observations led Goreau (1977) and Erez (1978) to propose two different models to explain carbon isotopic fractionation. The first author observed that ${ }^{13} \mathrm{C}$ increased with augmented light level. Indeed, algae and coral were thought to extract their inorganic carbon from the same reservoir for both photosynthesis and calcification processes. As photosynthesis is the faster reaction, lighter carbon isotopes were used preferentially; thus, the reservoir enriched in ${ }^{13} \mathrm{C}$ caused a $\delta^{13} \mathrm{C}$ increase with light (Goreau, 1977). The second author, after the observing the opposite, i.e., that $\delta^{13} \mathrm{C}$ decreased with light, proposed that during intense photosynthetic activity, it was possible that corals incorporated depleted metabolic carbon into their skeleton (Erez, 1978). None of these assumptions has been yet validated.

To explain the positive correlation between oxygen and carbon ratio, McConnaughey (1989a, b) assumed that the kinetic isotopic fractionation was strongly linked with calcification rate. After these publications, several theoretical models were put forth explaining how the observed coralskeleton isotopic fractionations were derived from a combination of kinetic and metabolic effects (Heikoop et al., 2000; McConnaughey, 2003; Omata et al., 2005).

Experiments conducted in the laboratory by Weil et al. (1981) showed a negative correlation between skeletal $\delta^{13} \mathrm{C}$ and light, i.e., the supply of autotrophic energy in the coral Montipora. Conversely, field experiments conducted by Swart et al. (1996) exhibited only weak correlations between skeletal $\delta^{13} \mathrm{C}$ and the supply of autotrophic energy, measured as the $P / R$ ratio (photosynthesis/respiration). Grottoli and Wellington (1999) later found a negative correlation between skeletal $\delta^{13} \mathrm{C}$ and the heterotrophic energy supply in the zooplankton and a positive correlation with light, i.e., the autotrophic energy supply. In addition, $\delta^{13} \mathrm{C}$ variability seemed decoupled from coral growth (Grottoli, 2002). Among these studies, only the laboratory experiments of Weil et al. (1981) deciphered the relations between the light and temperature effects and could document the effect of a single factor on metabolic activity and thus provide clear responses for the isotopic fractionations of oxygen and carbon.

It has been generally assumed that the geochemical response derived from several colonies is more significant than data provided by a single colony. Thus, authors have usu- ally considered averaged metabolic and chemical data from several colonies (Grottoli and Wellington, 1999; ReynaudVaganay et al., 1999, 2001; Grottoli, 2002; Suzuki et al., 2005). However, individual metabolic and isotopic responses can differ markedly. For instance, Acropora nubbins collected from a single parent colony and cultured in controlled SST conditions exhibited an inter-colony variability of $1 \%$ o (Reynaud-Vaganay et al., 1999). This has been confirmed for cultured Porites sp. (Suzuki et al., 2005), which showed similar variability at various temperature settings. In culture experiments, as in the field, coral $\delta^{13} \mathrm{C}$ showed larger intercolony variability than $\delta^{18} \mathrm{O}$, often $\geq 2 \%$ o (Reynaud-Vaganay et al., 1999; Suzuki et al., 2005).

The present work is based on data previously published by Reynaud-Vaganay et al. (2001), which examined the effect of light on the mean skeletal isotopic signatures $\left(\delta^{18} \mathrm{O}\right.$ and $\delta^{13} \mathrm{C}$ ) of several nubbins of Acropora sp. The effect of light was also measured on metabolic activities, such as photosynthesis, respiration, calcification rate and surface extension. In contrast with the preceding study, we now examined the individual coral responses. The results of this experiment conducted on Acropora were then compared with observations made by Gladfelter (1982) and we considered the possible relationship between skeletal growth and the relative roles of two crystalline microstructures. Finally, for climatic purposes, we compared the effects of a change in light intensity on a branched colony versus the time response of samples collected along the main growth axis of Porites.

\section{Materials and methods}

\subsection{Biological materials}

The experiment was conducted in the laboratory using colonies of the branching zooxanthellate scleractinian coral, Acropora sp. Tips from 24 branches were sampled from a single parent colony. The specimens were glued onto glass slides $(3 \times 6 \times 0.2 \mathrm{~cm})$ using underwater epoxy (Devcon) as described by Reynaud-Vaganay et al. (1999), and randomly distributed in two aquaria $(15 \mathrm{~L})$. The tanks were supplied with heated Mediterranean seawater $\left(24^{\circ} \mathrm{C}\right)$ pumped from a depth of $50 \mathrm{~m}$. The seawater renewal rate was approximately five times per day and the seawater was continuously mixed with a Rena pump $\left(6 \mathrm{~L} \mathrm{~min}^{-1}\right)$. Metal halide lamps (Philips HPIT, $400 \mathrm{~W}$ ) provided light of 260 or $130 \mu \mathrm{mol} \mathrm{m}^{-2} \mathrm{~s}^{-1}$ on a 12:12 photoperiod. Seawater was continuously aerated with outside air. The culture temperature $\left(25^{\circ} \mathrm{C}\right)$ was controlled to within $\pm 0.1^{\circ} \mathrm{C}$ using a temperature controller (EW, PC 902/T).

All colonies were initially cultured for six weeks under a light intensity of $130 \mu \mathrm{mol} \mathrm{m}^{-2} \mathrm{~s}^{-1}$ (referred to as Low Light, LL). Thereafter, colonies were cultured for six additional weeks under a light intensity of $260 \mu \mathrm{mol} \mathrm{m}^{-2} \mathrm{~s}^{-1}$ (High Light, HL). At the completion of each period and to 
determine the isotopic composition, the newly deposited ring skeleton which formed on the glass slide was collected with a scalpel (Reynaud-Vaganay et al., 1999), dried overnight at room temperature and stored in glass containers pending isotopic analysis.

During the experiment all potential variables (other than temperature and light) such as the chemical properties of seawater $(\mathrm{pH}$, salinity...) were strictly controlled and kept constant.

\subsection{Measurements of environmental parameters}

Irradiance was measured using a $4-\pi$ quantum sensor ( $\mathrm{Li}-$ Cor, LI-193SA) once a week (Table 1). Temperature (precision: $\pm 0.05^{\circ} \mathrm{C}$ ) was logged at 10 -min intervals using a Seamon temperature recorder.

Light intensities used in this experiment (130 and $260 \mu$ moles photons $\mathrm{m}^{-2} \mathrm{~s}^{-1}$ ) correspond to 5.6 and $11.2 \mathrm{~mol} \mathrm{~m}^{-2} \mathrm{~d}^{-1}$, respectively. Davies (1991) estimated that during a typical sunny day on a tropical reef a coral receives about $14.4 \mathrm{~mol} \mathrm{~m}^{-2} \mathrm{~d}^{-1}$ of sunlight at a depth of three meters in turbid water. On a cloudy day, the coral receives about $6.2 \mathrm{~mol} \mathrm{~m}^{-2} \mathrm{~d}^{-1}$ of sunlight. Thus, the light intensities in our experiments imitated a range from quite low to very strong natural illumination levels.

\subsection{Photosynthesis and respiration}

Photosynthesis and respiration were measured using the respirometry technique, which consists of measuring the changes in oxygen concentration during the incubation.

The experimental sequence was identical for each coral: each nubbin was taken from the culture aquarium, placed in a Perspex chamber $(240 \mathrm{ml})$ containing filtered seawater, for a 30-min pre-incubation in the light (130 or $260 \mu \mathrm{mol}$ photons $\mathrm{m}^{-2} \mathrm{~s}^{-1}$, depending on culture condition). The coral nubbin was then incubated for $1 \mathrm{~h}$ in the same chamber to measure the rate of photosynthesis. The chamber was then flushed and the coral pre-incubated for $30 \mathrm{~min}$ in the dark and then for $1 \mathrm{~h}$ in the dark to measure the respiration rate. During the incubation, the medium was continuously agitated using a magnetic stirrer and was changed after each incubation.

The respirometric chamber was kept at $25^{\circ} \mathrm{C}$ in a thermostatic water bath. All incubations took place between 08:00 and 14:00 $\mathrm{h}$. The colonies were subsequently returned to the culture aquarium. Oxygen concentration was monitored in the chamber and recorded every $1 \mathrm{~min}$ using a data-logger (LI-1000, Li-Cor Inc.). Dissolved $\mathrm{O}_{2}$ was measured using a Ponselle polarographic electrode calibrated daily against air-saturated seawater $(100 \%)$ and a saturated solution of sodium sulfite (zero oxygen). Rates of net photosynthesis and respiration were estimated using a linear regression of $\mathrm{O}_{2}$ against time. Photosynthesis and respiration values were then normalized to the skeletal surface area as estimated by the aluminum-foil technique (Marsh, 1970).

\subsection{Growth rates}

\subsubsection{Calcification rate}

Corals were weighed using the buoyant-weight technique (Jokiel et al., 1978; Davies, 1989) at the beginning and end of the experiment. The calcification rate was measured using the following formula:

$G=\sqrt[n]{\frac{P_{n}}{P_{0}}}-1$

Where $G$ is the calcification rate, $n$ is the number of the culture days, $P_{n}$ is the dry weight after $n$ days of culture and $P_{0}$ is the initial dry weight. Such a value indicates the percentage of weight increase relative to the initial weight per day.

\subsubsection{Surface extension}

Measurements are performed on the skeleton formed on the glass slide (Marsh, 1970). Thus, the corresponding size increase is the surface occupied by the newly-formed skeleton, receiving light perpendicularly.

\subsubsection{Thickening}

Thickening refers to the addition of new aragonite filling-in porosity or strengthening skeletal structure without noticeable horizontal surface extension.

\subsection{Isotopic measurements}

The isotopic values were calibrated against those determined by conventional methods using an Optima-VG mass spectrometer. Results are given in the conventional notation, expressed as per mil $(\delta \%$ ) against the V-PDB standard (Vienna Pee Dee Belemnite), where:

$\delta($ sample $)=\left[\left(R_{\text {sample }}-R_{\text {Standard }}\right)-1\right] \times 10^{3}$

The external precision, estimated using an internal standard, was \pm 0.11 and $0.08 \%$ vs. V-PDB for carbon and oxygen, respectively. The reproducibility of carbon and oxygen isotopic measurements, calculated from replicate coral samples, was 0.10 and $0.08 \%$ vs. V-PDB, respectively.

\section{Results}

All data are given in Table 1. This new interpretation of the data reported in Table 1 was based on a comparison of the behavior of each nubbin. Although nubbins were collected from a single parent colony, all measured parameters were highly variable. Measurements of some parameters were 
Table 1. Metabolic and isotopic measurements for each colony after 6 weeks of culture. All the nubbins have been submitted successively to low light and high light intensity during the same duration. For each light value, nubbins showing higher $\delta^{13} \mathrm{C}$ at HL than at LL are separated from the others (see Fig. 1).

\begin{tabular}{|c|c|c|c|c|c|c|c|}
\hline \# sample & & $\begin{array}{c}\text { Pnet } \\
\left(\mu \text { molcm }^{-2} \mathbf{h}^{-1}\right)\end{array}$ & $\begin{array}{c}\text { Resp } \\
\left(\mu \text { molcm }^{-2} \mathbf{h}^{-1}\right)\end{array}$ & $\begin{array}{c}\text { growth rate } \\
\% / \text { day }\end{array}$ & $\operatorname{surf}\left(\mathrm{cm}^{2}\right)$ & $\delta^{18} \mathrm{O} \%$ ovsPDB & $\delta^{13} \mathrm{C} \%$ ovsPDB \\
\hline \multicolumn{8}{|c|}{$130 \mu \mathrm{molcm}^{-2} \mathrm{~h}^{-1}$} \\
\hline 22 & \multirow{7}{*}{$\delta^{13} \mathbf{C}_{130}<\delta^{13} \mathbf{C}_{260}$} & 0.27 & -0.37 & 0.31 & 36.80 & -3.32 & -2.05 \\
\hline 49 & & 0.47 & -0.27 & 0.17 & 12.90 & -2.99 & -1.94 \\
\hline 21 & & 0.38 & -0.28 & 0.33 & 41.70 & -2.95 & -1.26 \\
\hline 23 & & 0.22 & -0.16 & 0.30 & 35.50 & -3.16 & -1.99 \\
\hline 55 & & 0.41 & -0.62 & 0.20 & 14.90 & -3.04 & -2.01 \\
\hline 66 & & 0.13 & -0.20 & 0.22 & 22.40 & -3.07 & -1.79 \\
\hline 68 & & 0.20 & -0.40 & 0.37 & 16.20 & -3.18 & -1.41 \\
\hline 48 & \multirow{8}{*}{$\delta^{13} \mathbf{C}_{130}>\delta^{13} \mathbf{C}_{260}$} & 0.34 & -0.23 & 0.20 & & -3.28 & -2.67 \\
\hline 24 & & 0.09 & -0.44 & 0.33 & & -3.20 & -1.99 \\
\hline 50 & & 0.51 & -0.46 & 0.21 & 9.70 & -3.00 & -2.50 \\
\hline 67 & & 0.27 & -0.54 & 0.23 & 12.10 & & \\
\hline 57 & & 0.29 & -0.17 & 0.02 & 17.70 & -3.03 & -2.53 \\
\hline 58 & & 0.29 & -0.25 & 0.18 & 14.70 & -3.29 & -2.52 \\
\hline 27 & & 0.36 & -0.34 & 0.41 & 20.90 & -3.06 & -2.14 \\
\hline 26 & & 0.09 & -0.15 & 0.40 & 25.40 & -2.95 & -2.03 \\
\hline \multicolumn{8}{|c|}{$260 \mu \mathrm{molcm}^{-2} \mathbf{h}^{-1}$} \\
\hline 22 & \multirow{7}{*}{$\delta^{13} \mathbf{C}_{130}<\delta^{13} \mathbf{C}_{260}$} & 0.57 & -0.34 & \multirow{7}{*}{$\begin{array}{l}0.66 \\
0.58\end{array}$} & 26.10 & -2.83 & -2.08 \\
\hline 49 & & 0.42 & -0.25 & & 8.30 & & -2.16 \\
\hline 21 & & 0.54 & -0.45 & & 19.20 & -2.82 & -1.88 \\
\hline 23 & & 0.53 & -0.23 & & 24.60 & -3.00 & -2.36 \\
\hline 55 & & 0.42 & -0.26 & & 13.60 & -2.78 & -2.17 \\
\hline 66 & & 0.29 & -0.24 & & 17.50 & -2.93 & -2.44 \\
\hline 68 & & 0.31 & -0.33 & & 10.00 & -2.69 & -1.66 \\
\hline 48 & \multirow{8}{*}{$\delta^{13} C_{130}>\delta^{13} C_{260}$} & 0.47 & -0.50 & \multirow[t]{2}{*}{0.78} & 12.50 & -2.93 & -1.75 \\
\hline 24 & & 1.01 & -0.65 & & 8.30 & -2.52 & -1.50 \\
\hline 50 & & 0.94 & -0.64 & \multirow[t]{2}{*}{0.60} & 8.20 & -2.21 & -0.76 \\
\hline 67 & & 2.55 & -0.31 & & 5.10 & -2.35 & -0.97 \\
\hline 57 & & 1.34 & -0.51 & 0.64 & 6.30 & -2.98 & -2.24 \\
\hline 58 & & 0.57 & -0.24 & 0.63 & 8.20 & -2.79 & -2.09 \\
\hline 27 & & 0.53 & -0.29 & & 14.00 & -2.50 & -1.49 \\
\hline 26 & & 0.26 & -0.22 & & 8.60 & -2.66 & -1.78 \\
\hline
\end{tabular}

lacking due to difficulties related with experimental conditions (Table 1). Herein, we examined metabolic and isotopic data provided by a single colony successively submitted to the two light conditions (from LL to HL; Fig. 1).

\subsection{The effect of light}

We note that metabolic and chemical data are highly scattered (Fig. 1a). For instance, $P_{\text {net }}$ variability was lower at LL $\left(0.5 \mu \mathrm{mol} \mathrm{cm}{ }^{-2} \mathrm{~h}^{-1}\right)$ than at $\mathrm{HL}$ (the amplitude was $>2 \mu \mathrm{mol} \mathrm{cm} \mathrm{cm}^{-2} \mathrm{~h}^{-1}$ ), likewise $\delta^{18} \mathrm{O}$ varied by $0.5 \%$ at $\mathrm{LL}$ and $1 \%$ at HL. But respiration variability was high for the two light conditions, from -0.6 to $-0.2 \mu \mathrm{mol} \mathrm{cm} \mathrm{ch}^{-2} \mathrm{~h}^{-1}$, as well as $\delta^{13} \mathrm{C}$ values showing for the two conditions around $1.5 \%$ of amplitude. The trend shown by all nubbins between LL and HL was identical for all the measured parameters, except for $R$ and $\delta^{13} \mathrm{C}$. The significance of a unanimous metabolic or chemical response is stronger than a trend revealed after averaging data.
Figure $1 \mathrm{~b}$ clearly indicates that light increase led to intensified net photosynthesis and increased calcification (in terms of percentage of growth per day), but also led to a decrease of surface extension and $\delta^{18} \mathrm{O}$ enrichment. Respiration variability showed identical range during the two light conditions. The $\delta^{13} \mathrm{C}$ change was more confusing with half of the nubbins exhibiting increased values and the other half showing decreased values between low and high light.

\subsection{Partitioning into two groups}

We expected an unique response, thus in order to highlight our results, we divided the nubbins into two groups: those showing a $\delta^{13} \mathrm{C}$ increase from LL to HL (the expected response according to the global carbon-pool assumption, Goreau, 1977) (Fig. 1c, light color) and those showing a $\delta^{13} \mathrm{C}$ decrease (i.e., the expected response in case of uptake of ${ }^{13} \mathrm{C}$ depleted metabolic carbon, Erez, 1978) (Fig. 1c, dark color). 

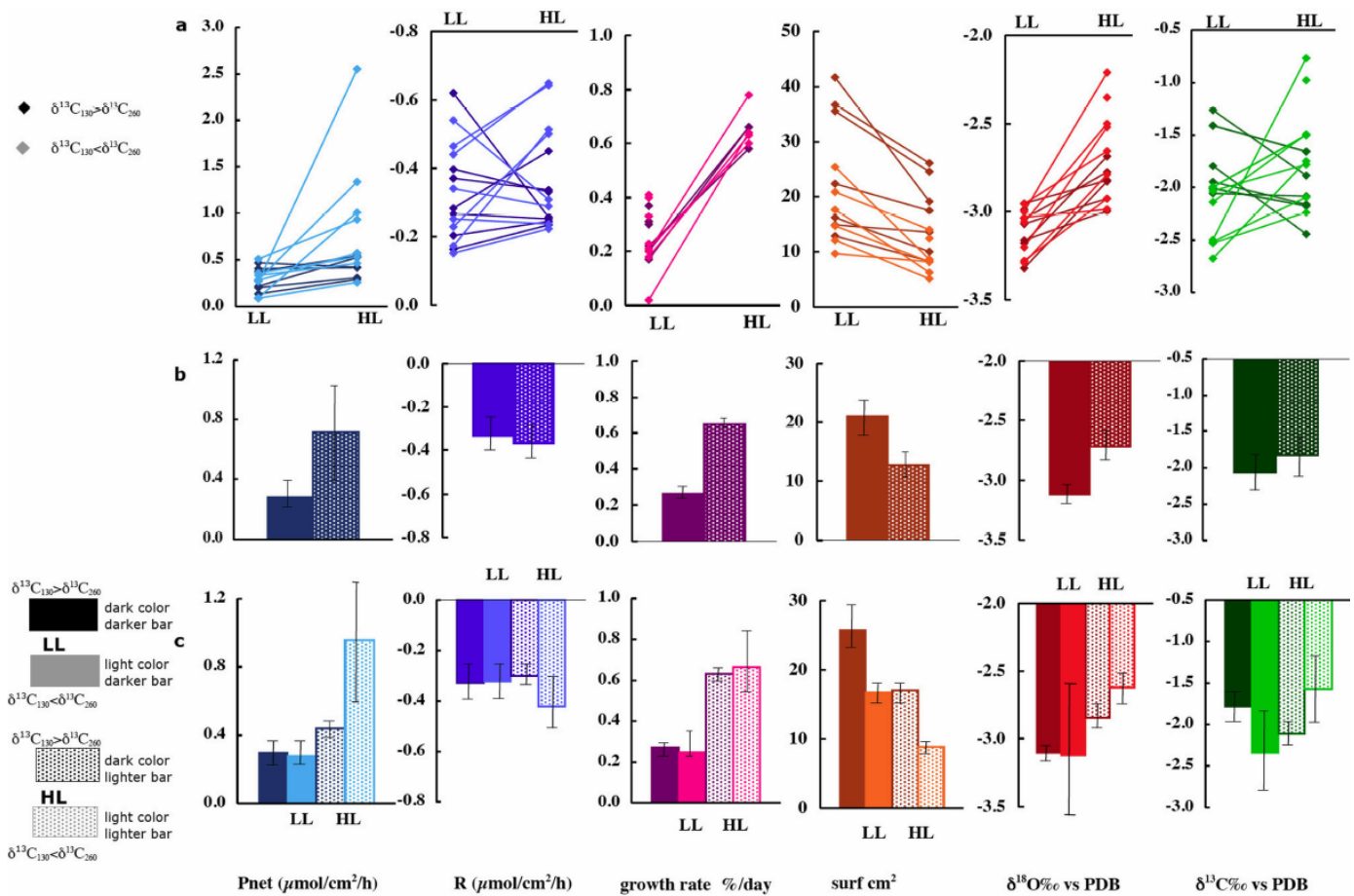

Fig. 1. Values of measured metabolic and geochemical parameters. (a) Values of each nubbin are plotted for high and low light. Light (dark) color corresponds with colonies showing higher (lower) $\delta^{13} \mathrm{C}$ at HL than at LL. To underline the individual variability shown by one nubbin, HL and LL dots are linked. (b) At each light condition values of all nubbins have been averaged. Darker bars are associated with LL and lighter ones with HL (plotted error: $2 \sigma$ ). We notice that in this case, $R$ or $\delta^{13} \mathrm{C}$ were almost identical at LL and HL. (c) Averaged values for each light condition calculated after splitting nubbins into two groups: light (dark) color corresponds with colonies showing higher (lower) $\delta^{13} \mathrm{C}$ at HL than at LL. Darker bars are associated with LL and lighter ones with HL (plotted error: $2 \sigma$ ).

At LL (Fig. 1c, darker bars), the two groups exhibited similar net photosynthesis, respiration, growth rate and $\delta^{18} \mathrm{O}$. Values were more scattered for surface extension and $\delta^{13} \mathrm{C}$. By examining the responses at HL (Fig. 1c, lighter bars), we realized that metabolic and isotopic values shown by these two groups presented common features. Colonies showing lower $\delta^{13} \mathrm{C}$ at HL than at LL (Fig. 1c, dark color, lighter bar) were associated with larger surface extension and the others characterized by higher $\delta^{13} \mathrm{C}$ than at $\mathrm{HL}$ (Fig. 1c, light color, lighter bar) exhibited the smallest surfaces.

Colonies displaying higher $\delta^{13} \mathrm{C}$ at $\mathrm{HL}$ (Fig. 1c, light color, lighter bar) showed higher photosynthetic activity and the most enriched $\delta^{18} \mathrm{O}$ and $\delta^{13} \mathrm{C}$ values. Surface extensions of the nubbins showing lower $\delta^{13} \mathrm{C}$ (Fig. 1c, dark color, lighter bar) were almost all greater than that measured on the nubbins showing higher $\delta^{13} \mathrm{C}$ but always lower than that measured at LL. For the two groups (Fig. 1a, clear and dark color, lighter bar), the weight of colonies at least doubled during the incubation, while surface extension was weaker by ca. $40 \%$ (Fig. 1c). The $\delta^{18} \mathrm{O}$ of all colonies increased, the enrichment being more pronounced for colonies showing an increase in $\delta^{13} \mathrm{C}$ (Fig. 1c, light color, lighter bar).

The averaged values calculated after partitioning were more significant than earlier values published for all the colonies (Fig. 1b) (Reynaud-Vaganay et al., 2001). We noticed that all intermediate values between the highest and lowest $\delta^{13} \mathrm{C}$-differences between LL and HL were recorded. This explains why the difference in the $\delta^{13} \mathrm{C}$ average (Fig. 1b) was not significant (Reynaud-Vaganay et al., 2001).

We plotted on Fig. 2 all the possible relationships between the measured parameters. There is not noticeable correlation. In opposite to what is usually thought, there is no clear correlation between $\delta^{13} \mathrm{C}$ and $P_{\text {net }}$, neither between $\delta^{13} \mathrm{C}$ and $R$.

\subsection{Duality of metabolic and isotopic responses at HL}

The partitioning of the colonies into two groups, according to the sign of the $\delta^{13} \mathrm{C}$ change between LL and HL, underlines various metabolic responses previously ignored.

At HL, the nubbins showing lower $\delta^{13} \mathrm{C}$ (Fig. 1c, dark color, lighter bar) corresponded to lower productivity associated with the highest surface extension (Fig. 3). $P_{\text {net }}$ and surface extension $(S)$ are roughly linearly correlated:

$S=0.01 \cdot P_{\text {net }}+0.25$ with $R^{2}=0.46$ for $N=8$

where $N$ is the number of nubbins. 


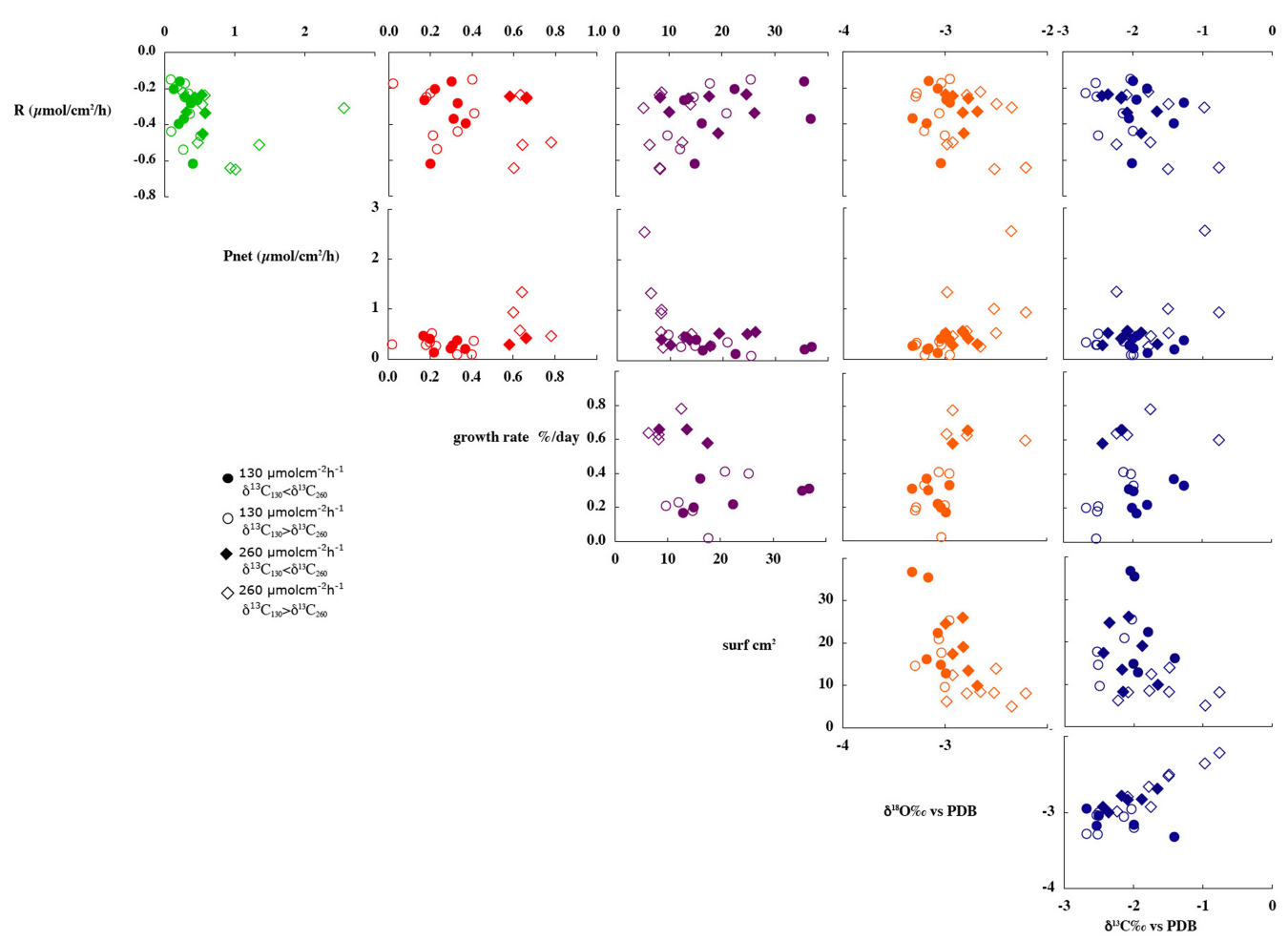

Fig. 2. Comparison of all measured metabolic and isotopic parameters. Circles correspond to data obtained at LL, diamonds to HL. Clear (dark) symbols are associated to colonies showing lower (higher) $\delta^{13} \mathrm{C}$ at HL than at LL. Linear correlation is clear between $P_{\text {net }}$ and $R$ for the highest values of $P_{\text {net }}$, between surface and growth rate and between $\delta^{18} \mathrm{O}$ and $\delta^{13} \mathrm{C}$.

At HL, colonies showing higher $\delta^{13} \mathrm{C}$ (Fig. 1c, light color, lighter bar) were those displaying higher productivity associated with the lowest surface extension (Fig. 3). The parameters are also weakly correlated:

$S=-0.17 \cdot P_{\text {net }}+2.48$ with $R^{2}=0.48$ for $N=7$

The correlation coefficients were not significant; however they do not invalidate the suggestion of two different behaviors related to light intensity. Under HL, corals may display one of the two behaviors linked with photosynthetic activity: either photosynthesis activity slightly increases and surface extension remains noticeable (although lower than at LL) or photosynthesis is clearly enhanced and surface extension strongly reduced.

Photosynthetic activity and respiration were correlated for colonies showing the highest photosynthesis $\left(P_{\text {net }}>0.6\right)$ (Fig. 2). However, as there were only four data points, this relationship needs to be confirmed by additional experiments. There was no correlation between isotopic data and metabolic indicators (Fig. 2).

For $\delta^{13} \mathrm{C}$ versus $\delta^{18} \mathrm{O}$ (Fig. 4), there was no relation at LL (circles) but at HL (diamonds) the relationship was significant: $\delta^{13} \mathrm{C}=1.92 \cdot \delta^{18} \mathrm{O}+3.41$ with $R^{2}=0.86$ for $N=14$ (3) (Fig. 4). We note that skeletal $\delta^{18} \mathrm{O}$ values were also more positive in those showing a more positive $\delta^{13} \mathrm{C}$ at $\mathrm{HL}$ than at LL (clear circles), whereas the other $\delta^{18} \mathrm{O}$ values were

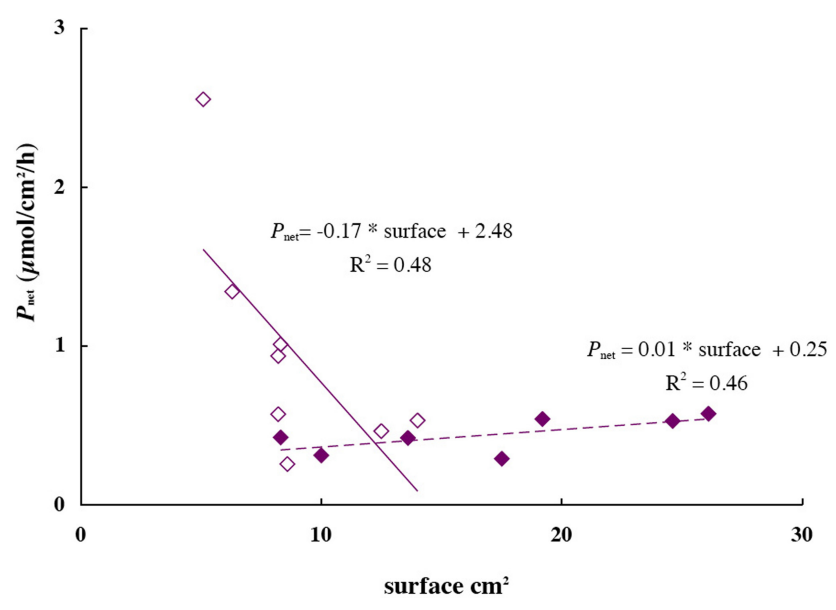

Fig. 3. Photosynthetic activity versus surface covered by newformed aragonite at HL. Darker symbols correspond to colonies showing higher $\delta^{13} \mathrm{C}$ at $\mathrm{HL}$ than at LL. $P_{\text {net }}$ values measured on colonies showing lower $\delta^{13} \mathrm{C}$ than at LL, are limited to $1.6 \mu \mathrm{mol} \mathrm{cm} \mathrm{cm}^{-2} \mathrm{~h}^{-1}$ and are associated with development on larger surface than colonies showing higher $\delta^{13} \mathrm{C}$ than at LL and responding with higher photosynthetic activity, though all the nubbins respectively almost doubled their skeleton weight. Correlation coefficients of the lines plotted on the figure are not significant, however, full and empty diamonds clearly show two distinct behaviors. 


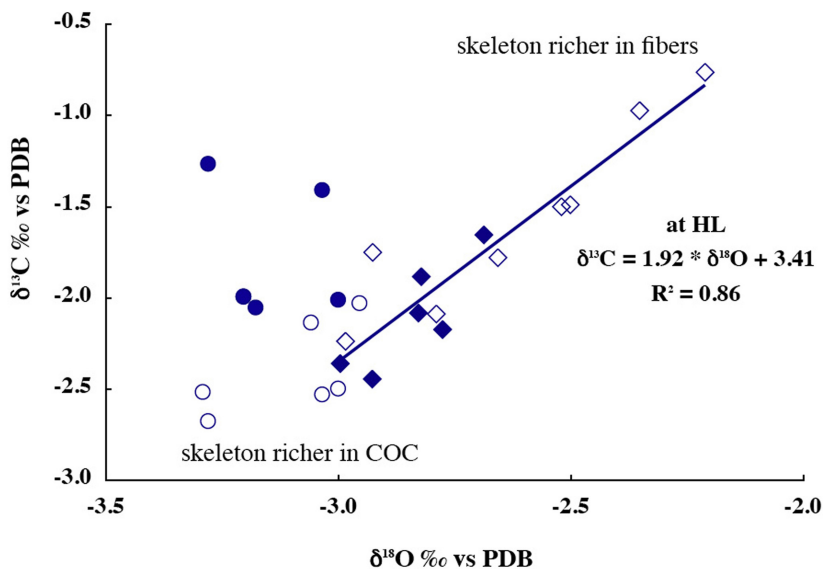

Fig. 4. $\delta^{18} \mathrm{O}$ value of individual specimen plotted against $\delta^{13} \mathrm{C}$. At HL (diamonds) $\delta^{18} \mathrm{O}$ and $\delta^{13} \mathrm{C}$ are linearly correlated, with a significant correlation coefficient. The highest $\delta^{18} \mathrm{O}$ and $\delta^{13} \mathrm{C}$ data correspond to the nubbins responding strongly to HL. These samples could be rich in fibers, whereas the samples showing both low $\delta^{18} \mathrm{O}$ and $\delta^{13} \mathrm{C}$ could be richer in COC.

roughly within the same range as for LL (Figs. 2 and 4). Indeed, at HL few $\delta^{18} \mathrm{O}$ showed lower values than $-3.0 \%$.

We highlighted the unexpected light effects on $\delta^{18} \mathrm{O}$ (Reynaud-Vaganay et al., 2001). The discrepancies in metabolic behavior at HL exhibited by $\delta^{13} \mathrm{C}$ variability were also not expected. We sought to highlight how modifications in the host metabolism may impact chemical properties of the coral skeleton.

\section{Discussion}

This experiment confirmed that calcification is lightenhanced (Goreau and Goreau, 1959; Chalker, 1981; Gattuso et al., 1999) because each nubbin showed an increased calcification with increased light. At HL, all nubbins at least doubled their initial weight in respect with calcification at LL, whereas surfaces covered by the newly-formed skeleton remained smaller. As such, we consider that surface extension is light-suppressed.

\subsection{Metabolic imprint on skeleton chemistry}

The culture technique used here allowed us to separate temperature from light effects on the skeletal isotopic signature and metabolic parameters. Clode and Marshall (2004) have tested the role of light on the calcification rate of a zooxanthellate (Galaxea) and azooxanthellate (Dendrophyllia) coral, using the ${ }^{45} \mathrm{Ca}$ technique. Galaxea and Dendrophyllia presented similar $\mathrm{Ca}^{2+}$ incorporation versus temperature over the range of $18-29^{\circ} \mathrm{C}$, and authors have concluded that the calcification process was affected by temperature but was probably not associated with photosynthesis. This previous experiment, however, used different species displaying different metabolic specificities and moreover, temperature and light effects were mixed. Thus, the data could not be compared and it could not demonstrate the solely photosynthetic influence. Other factors could explain the difference of $\mathrm{Ca}$ incorporation, e.g., temperature or differences in calcification rate among species. Conversely, our experiment avoided the temperature effect and examined the response of nubbins originating from one species, even a single parent colony, thus all were supposed to present identical metabolic and morphological characteristics.

As the experiment was conducted on nubbins originating from a single parent colony the isotopic scattering observed might be compared with inter and even intra-colony $\delta^{18} \mathrm{O}$ variability exhibited by Porites collected at Clipperton (Linsley et al., 1999) or in Indonesia (Maier et al., 2004). Moreover, by considering isotopic effects of a single nubbin successively submitted to two light intensities we have an identical approach than when we examine $\delta^{18} \mathrm{O}$ variation along close corallites representing mineral deposited during two successive months. The results obtained showed that the average of several responses could mask the significance of the individual behavior (Weil et al., 1981; Grottoli and Wellington, 1999; Grottoli, 2002).

\subsection{Light effects on growth}

Increased light was systematically associated with an increase of skeletal weight and a decrease of surface extension of newly-formed skeleton during identical duration. The coupled effects generated an increase in skeletal density. Acropora usually does not show clear annual density bands; however, this experiment presents proof that light affects Acropora density. This could also be related to observations made on Porites most often producing low-density bands during winter (Lough and Barnes, 2000), but it is important to keep in mind that, in the field, light effects may be obscured by other factors such as temperature and/or reproductive cycles (Mendes, 2004).

This light effect observed can provide an explanation for data from the Caribbean Sea. When Montastrea annularis was submitted to unfavorable conditions (lower light and anthropogenic influence), they appeared to "sacrifice skeletal density while maintaining or increasing skeletal extension, despite having a lower calcification rate" (Cruz-Piñon et al., 2003) (see also Carricart-Ganivet, 2004). Although in our experiment we measured surface extension and not linear extension, these field observations are roughly in agreement with what we observed at LL. Is the extension an expression of growth compensation when luminosity is insufficient, or is there a competition between the two growth rates? At LL, the extension rate was always higher than at HL (Fig. 2), and, at HL, when photosynthesis was intense, extension was reduced (Fig. 3). Nubbins showing higher extension than the other colonies at LL seemed to roughly keep this specificity 
at HL without being able to produce strong photosynthetic activity. However, among these colonies, there was a positive correlation between extension and net productivity (Fig. 3).

The partitioning of the colonies into two groups stresses that the two growth features, surface extension rate and weight of deposited aragonite per time unit (calcification rate), are distinct processes (Fig. 1c). It has been noted previously that these two measurements of coral growth are not redundant and may provide complementary information (Scoffin et al., 1992). However, we wanted to understand why nubbins originating from one parent colony presented two different behaviors.

\subsection{The role of zooxanthellae}

Earlier we noted that the $\delta^{13} \mathrm{C}$ responses exhibited all intermediate values between the two extremes, likewise, the metabolic responses, especially photosynthesis and surface extension were highly scattered (Fig. 1). By examining Fig. 5 we observe that one side of the colony (A side) presented thickened skeleton (not expanded on the glass side) surrounding the axial corallite. This illustrates the growth mode called "thickening" in the first part of this article, which is observed on the inter-corallite spaces and at the base of corallite. The other side of the axial corallite ( $\mathrm{B}$ side) is composed of newly-formed corallites (Juillet-Leclerc et al., 2009). By comparison with the description of Acropora hyacinthus given by Nothdurft and Well (2007), they could be called radial corallites, which are growing vertically in the field. The surface extension measured during our experiment might be assimilated to linear extension. We suggest that the aragonite collected on the glass slide (Fig. 4) integrated variable amounts of skeleton fragments, with metabolic and also isotopic measurements integrating the relative responses; this could also explain the large scatter of our data.

Although we did not measure algal abundance, we could relate the different growth modes observed at HL to highly variable efficiency of photosynthesis due to different densities of zooxanthellae. Figure 3 indeed suggests that skeletons showing the maximal extension are poorer in algal density, leading to a low $P_{\text {net }}$. Weber et al. (1976) stressed this specificity in Acropora cervicornis. They observed that the abundance of symbiotic zooxanthellae increased from the tip to the base of a branch. They associated this difference with rather confused isotopic behaviors for $\mathrm{O}$ and $\mathrm{C}$. This observation, which supports our interpretation, could be counterintuitive. Indeed, the upper surface of the coral, where skeletogenesis seems to start, receiving more direct light incidence could be supposed to be richer in algae than the sides of colonies, which receive less intense light.

We assumed that the highest $\mathrm{O}$ and $\mathrm{C}$ isotopic values were provided by samples essentially composed of skeleton portions corresponding to the sides of corallites or to the skeletal zone called inter-corallites, having the ability to strongly photosynthesize, while the samples characterized by low

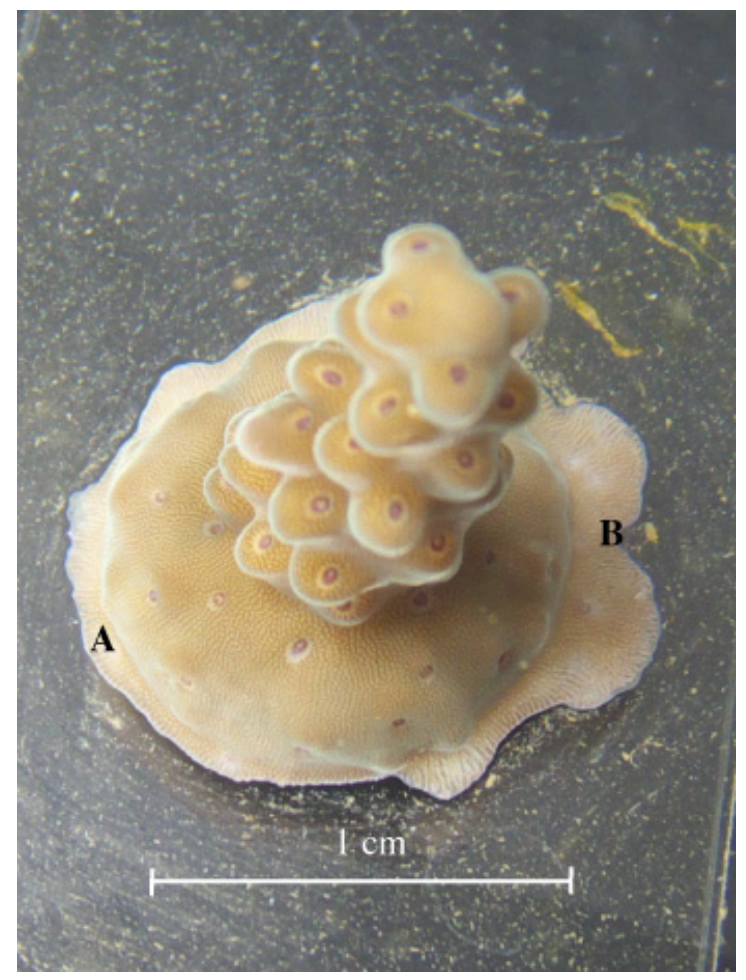

Fig. 5. Acropora nubbin after few week growth at HL. New-formed aragonite is deposited on the colony and the glass slide. On side A, the layer of new mineral is reduced and thick, whereas on side B it extends further the initially stuck nubbin and new corallites are visible. We cannot attribute such a discrepancy to different light incidences, on the glass slide, all the portions of the new-formed skeleton received identical light intensity. On the A side at the level of the section of the branched coral is essentially formed by fibers capable to thicken the skeleton under HL. On the B side, the section of the branch coral contain COC, of which growth is light-repressed. Such portion of nubbin could be much more developed under LL.

$\delta^{13} \mathrm{C}$ contained greater amounts of aragonite forming the radial and central corallite tips according to observations made by Weber et al. (1976).

It seems that at HL, when photosynthesis was clearly active, respiration proportionally decreased (Fig. 2). This observation could be due to a part of the respired $\mathrm{CO}_{2}$ being used for photosynthesis, as in the carbon-translocation hypothesis of Muscatine and Porter (1977). However, we have no information to document a mechanism linking the metabolic activity of algae with coral metabolism leading to modifications in skeletogenesis.

\subsection{Is there competition between photosynthetic activity and surface extension?}

Figure 3, obtained with samples maintained at HL, highlights an inverse relationship between photosynthesis and surface extension. Indeed, the group of colonies showing reduced photosynthesis and $\delta^{13} \mathrm{C}$ depletion with the augmented light 
also presented an increase in surface extension, while the group showing an active photosynthesis was characterized by the lowest extension. On one hand, this could illustrate competition between surface extension and photosynthetic activity at HL, while, on the other hand, it could indicate that there are two biomineralization strategies: submitted to HL, some parts of the skeleton are dedicated to spatial growth and the others to strengthening skeletal structure. We note that the relative growth weight doubled in both cases.

\subsection{Axial and lateral portions of a corallite}

Gladfelter (1982, 1983, 1984) investigated the skeletal growth pattern of Acropora cervicornis. She described the wall of an axial corallite, surrounding the calyx, formed by vertical spines connected together tangentially and radially by a porous mineral (Gladfelter, 1982). She identified two different growth units: massive, randomly oriented crystals, called fusiform crystals, and numerous needle-like crystals projecting in many directions from the fusiform crystals. She noted that the needles, which were gathered into bundles oriented perpendicularly to the spine, showed a progressive filling-in of pore space from the tip of the corallite to the base. She deduced from these observations that skeletogenesis could be the result of two processes: the deposition of fusiform crystals and the progressive thickening of the initial framework by needle-like crystals. She attributed these two modes of deposition to a dichotomy in growth axes: the axial growth most often expressed as a linear extension resulting from the deposition of fusiform crystals, with lateral accretion by fibers ensuring the strengthening of the skeleton (Gladfelter, 1982, 1984). These investigations led her to conclude that the first step of skeletogenesis was performed during the night, while the main parameter influencing the second was the duration of sunlight per day (Gladfelter, 1983).

The differentiation of coral-skeleton growth relative to its shape could be a specific feature of branched corals such as Acropora. Skeletal structure has also been studied in Porites (Barnes and Lough, 1993). Like Gladfelter (1983), these authors also proposed skeletal development in two steps. Lough and Barnes (2000) observed different rates of extension and calcification between the top and sides of colonies in numerous massive Porites from the Great Barrier, which led them to attribute the observed discrepancy to light availability. Like Gladfelter (1982), they noted the coral growth dichotomy.

SEM microstructural observations of several coral genera led Cuif and Dauphin (1998) to also suggest that coralskeleton deposition operated into two successive steps. Also from SEM observations, Nothdurft and Webb (2007) underlined common features and discrepancies shown by several coral genera, the presence of two growth units and two growth modes appearing as common features to everyone. At another size scale, it has been demonstrated that calcification of Stylophora pistillata also operates by two mecha- nisms: first extension and secondly progressive filling-in of the previously deposited structure (Raz-Bahat et al., 2006).

\subsection{The link between light, skeletal microstructures and growth modes}

Isotopic measurements conducted at the micrometer scale on cultured Acropora, similar to the colonies studied here, (Juillet-Leclerc et al., 2009) confirmed that the fusiform crystals stressed by Gladfelter (1982), abundant around the theca of Acropora, were identical with centers of calcification (COC) or early mineralization zones (EMZ) like those observed along the trabecula by other authors (Cuif and Dauphin, 1998, 2003; Raz-Bahat et al., 2006; Nothdurft and Webb, 2007).

Although earlier observations and the present study are based on two different size scales, our experiment indicated that coral growth followed one main axis and a perpendicular plan corresponding to two separate processes. Our results also suggest that extension ensured by COC is lightsuppressed whereas thickening, in term of filling-in or consolidation by fiber bundles, is light-enhanced. Photosynthetic activity of the lateral portion of a corallite, assumed to be less exposed to light, was more intense than at the corallite tips because the sides would be likely richer in algae (Weber et al., 1976). The same paradox at the crystal scale was stressed in Stylophora pistillata observations by combining Field Emission Scanning Electron Microscopy (FESEM) and supplementary fluorescence techniques (Tambutté et al., 2007).

As shown in Fig. 5, there was a side (A side) where the newly deposited mineral corresponded essentially to accretion of fibers with some spinules containing few COC but free of calyces, forming a thick and dense aragonite layer around the axial polyp, while on the other side (B side) the new mineral was rich in new calyces with COC at their tip and also in the radial septae. Thus, the relative proportion between COC and fibers depends on the location of the nubbin section, which explains why superficial extension of several nubbins may be as different as noted during this experiment. Juillet-Leclerc et al. (2009) demonstrated that, in a colony grown at constant conditions, $\mathrm{COC} \delta^{18} \mathrm{O}$ is almost constant and centered on the lowest value, while fiber $\delta^{18} \mathrm{O}$ varies over a 5\%o-amplitude range, from the equilibrium value to the lowest one, the latter isotopic behavior likely being linked with kinetics of deposition process. This could explain the high variability exhibited by nubbins from a single parent colony due to the highly variable relative crystal amounts, which is a crucial factor determining isotopic value. Additionally, the skeleton developed on the glass slide received identical light over the whole surface (which is not the case on the side of a wild colony), thus, the effect on the different portions of the skeleton is amplified.

We emphasize that, in the case of Acropora, the space between each calyx is more developed than in other genera such 
as Porites (Nothdurft and Webb, 2007). This skeletal difference may also likely serve to amplify the discrepancies between several nubbins.

\subsection{Relationship between growth and isotopic values}

We demonstrated that HL enhanced fiber formation (JuilletLeclerc et al., 2009). Therefore, knowing that $\delta^{18} \mathrm{O}$ in fibers is always higher than $\delta^{18} \mathrm{O}$ in $\mathrm{COC}$, we suggest that the systematic positive $\delta^{18} \mathrm{O}$ response to light increase (Fig. 1a) was due to fiber enrichment in all the colonies. This conclusion is supported by the fact that the positive isotopic response was more pronounced in colonies responding actively to light through photosynthesis (Fig. 1c). Additionally, we note that when photosynthesis was strongly active, $\delta^{18} \mathrm{O}$ signature was higher. Moreover, the oxygen reservoir was isotopically constant over the incubation period, as the atoms came from seawater where they are abundant.

Meibom et al. (2006) showed that the $\operatorname{COC} \delta^{13} \mathrm{C}$ of Colpophyllia sp. were lower than that of the fibers. This could explain why at HL, colonies strongly sensitive to photosynthesis (likely richer in zooxanthellae) exhibited higher values than the others. At $\mathrm{LL}$, the $\delta^{13} \mathrm{C}$ of colonies richer in $\mathrm{COC}$ would then be lower than those containing mainly fibers. Curiously, we observed the opposite (Fig. 4). In addition, these nubbins showed lower $\delta^{13} \mathrm{C}$ at HL (Fig. 4). In the case of carbon, the origin of the atoms might vary between the two conditions. Indeed, Rollion-Bard et al. (2003a) demonstrated that $\delta^{18} \mathrm{O}$ and $\delta^{13} \mathrm{C}$ measured in a single sample at the micrometer scale were not always correlated. We previously noted that the results considered in the present study were formed by the integration of numerous isotopically heterogeneous microstructures. At the macro scale, due to natural integration, $\delta^{18} \mathrm{O}$ and $\delta^{13} \mathrm{C}$ may thus be correlated. Therefore, to explain $\delta^{13} \mathrm{C}$ variations, we must assume that, in addition to the fractionation due to kinetic processes, the carbon reservoir has to differ. Biological investigations using double labeling $\left({ }^{14} \mathrm{C}\right.$ and ${ }^{45} \mathrm{Ca}$ ) (Erez, 1978; Furla et al., 2000) demonstrated that in the case of active photosynthesis, the amount of carbon present in the symbiotic system is not sufficient to sustain physiological activities, and this lack of carbon is compensated by an increase of seawater-uptake by the coral tissue. Considering that Dissolved Inorganic Carbon DIC seawater $\delta^{13} \mathrm{C}$ is much higher than metabolic $\delta^{13} \mathrm{C}$, skeletal $\delta^{13} \mathrm{C}$ should be enriched, supporting the macroscale observations.

In addition, deposition processes of each crystal type differ as well as their isotopic signatures (Juillet-Leclerc et al., 2009). Therefore, we also can explain isotopic discrepancies existing between different nubbins (Fig. 1). Some of our samples contained mainly fibers, thus showing at $\mathrm{HL}$ an increase of $\delta^{18} \mathrm{O}$ and $\delta^{13} \mathrm{C}$ associated with the lowest extension rate (Fig. 1c). For the other nubbins richer in COC, HL enhanced only the growth of their fibrous portion, enriching the $\delta^{18} \mathrm{O}$ signature but decreasing the extension rate. The pri- mary skeletal carbon origins then changed between LL and $\mathrm{HL}$, and the global effect on the $\delta^{13} \mathrm{C}$ values of "bulk" samples was variable.

\section{$4.8 \quad \delta^{18} \mathrm{O}$ and $\delta^{13} \mathrm{C}$ correlation}

The high $\delta^{18} \mathrm{O}$ and $\delta^{13} \mathrm{C}$ correlations of seasonal samples and samples collected horizontally around Pavona clavus heads and simultaneously deposited led McConnaughey (1989a and b) to assume kinetic isotopic fractionation in the coral skeleton. The distribution of $\delta^{18} \mathrm{O}$ and $\delta^{13} \mathrm{C}$ in Porites aragonite sampled along the faster growing axis appeared to be caused by the relative variability of temperature and light. The two interpretations were consistent: the upper surface of the coral head received more sunshine, thus grew faster and showed depleted $\delta^{18} \mathrm{O}$ while the lateral surfaces, receiving less light, exhibited a slower growth rate and higher $\delta^{18} \mathrm{O}$ (McConnaughey, 1989a). Therefore, it has been concluded that when $\delta^{18} \mathrm{O}$ and $\delta^{13} \mathrm{C}$ were correlated this could indicate the skeleton deposition following a kinetic process; negative oxygen fractionation has been associated with high growth rate and high light, $\delta^{18} \mathrm{O}$ being affected by temperature and $\delta^{13} \mathrm{C}$ by photosynthesis. Our experiment highlights that it is not so simple.

$\delta^{18} \mathrm{O}$ and $\delta^{13} \mathrm{C}$ are both affected by light (Fig. 1). However, light effects are not equivalent on all skeletal microstructures and thus the isotopic analyses are more or less impacted by the integration of micro-isotopic signatures. This leads to non-homogeneous isotopic distribution, with strong variations according to the morphology. Linear extension and calcification are distinct kinetic processes, responding differently to light. Thus, relationships between kinetics and isotopic fractionation and between kinetics and light are more complex: in Acropora sampled at the macro-scale, the kinetic imprint on isotopic fractionation due to fiber growth is sensitive because fibers are the most numerous skeletal components. Only oxygen is purely fractionated through a kinetic process; $\delta^{13} \mathrm{C}$ is determined by the combination of reservoir change and kinetic fractionation according to the metabolic activity. We note that oxygen and carbon isotope correlation was essentially significant under HL because it was only in these conditions that photosynthesis activity and thus thickening, responsible for the $\mathrm{O}$ and $\mathrm{C}$ correlation, was really active (Fig. 4).

\subsection{Consequences for paleoclimatic investigations}

The present experiment performed on cultured Acropora highlights the behavior of a single coral clone, potentially inhabited by different concentrations of zooxanthellae and maintained under two light conditions. Each aragonite measurement includes an axial corallite plus some radial corallites. Our conclusions make sense only by comparing the same initial corallite subject to different conditions. Although morphology and micro-structure distribution differ 
between Acropora and Porites, the conclusions inferred from our study may be extended to the time series usually developed for Porites paleoclimatic studies.

The common sampling method used for paleoclimatic studies systematically follows the major growth axis of the coral. By examining samples collected on a profile over time, we record the chemical response to environmental seasonal changes of corallites derived from identical clones and probably inhabited by similar symbiont assemblages. Additionally, this means that the sample profile corresponds to an area where COC constitute the largest portion of microstructures and where photosynthetic activity influence is reduced, in contrast to the initial assumptions commonly formulated. This confirms conclusions earlier proposed for Acropora and probably for other genera (de Villiers et al., 1995; Cardinal et al., 2001) that extension is not linear during the year. We add that extension decreases with more light. Thus, we should take into account such a feature to correctly record and convert environmental changes in a given chronology. This emphasizes the importance of the sampling mode along corallites always being oriented along a similar direction during the study period and showing an apparent continuity by Xray imaging.

In contrast with the commonly held belief, linear extension of coral does not respond positively to light. We cannot apply systematic corrections to $\delta^{18} \mathrm{O}$ as proposed by Maier et al. (2004). However, we must assume that metabolic activity, essentially photosynthetic activity, is roughly reproducible each year, even when the algal assemblage is slightly modified over time. Two adjacent areas horizontally sampled on a single coral head may host different algal assemblages and algal concentrations and this could explain the great variability in isotope signals as reported by Linsley et al. (1999), Felis et al. (2003) and Maier et al. (2004).

At the millimeter scale, it would be difficult to observe simple relationships between isotopic signatures and metabolic activity due to the presence in the bulk sample of variable relative amounts of crystals characterized by different isotopic fractionations.

As light and temperature often vary in parallel but have opposite effects, the amplitude of $\delta^{18} \mathrm{O}$ fluctuations only due to temperature will always be smoothed by the effect of light through photosynthetic activity. This could explain the observed high variability of time series and calibrations (Wellington et al., 1996; Linsley et al., 1999; Maier et al., 2004). It could also explain the correlation of $\delta^{18} \mathrm{O}$ versus SST showing lower absolute slope values than $-0.20 \%{ }^{\circ} \mathrm{C}$ (Juillet-Leclerc and Schmidt, 2001; Suzuki et al., 2005). Thickening of the corallite wall could also smooth $\delta^{18} \mathrm{O}$ by the addition of aragonite fibers. Due to a specific morphological organization, especially a reduced inter-corallite surface, this effect would likely remain limited for Porites compared with Acropora; sampling along the axis of maximum growth rate would also reduce this effect.
We note that linear extension and $\delta^{18} \mathrm{O}$ are affected by light in the same way; the direct temperature effect and that caused through photosynthesis are opposite. It would be informative to compare $\delta^{18} \mathrm{O}$ and linear-extension fluctuations over a year, but extension variability is not easy to measure over a year. The light influence on $\delta^{13} \mathrm{C}$ is more complex and depends on the corallite portion sampled.

Our findings help explaining the contrasting observations made on different colonies (Goreau, 1977; Erez, 1978). However, on a Porites head, as sampling is centered along the main growth axis where COC are abundant, a clear $\delta^{13} \mathrm{C}$ decrease is almost always recorded with light enhancement during the summer (Swart et al., 1996).

\section{Summary}

1. Rates of photosynthesis are not constant or equal on the surface of a coral skeleton. Zooxanthellae could also be more abundant on the sides than on the apex of corallites. Light enhancement leads to decreased extension rate and increased aragonite weight deposited. Thus, HL causes a skeleton-density increase. Although the absence of algae on the apical part of the skeleton is counter-intuitive following classical geochemical hypothesis, several lines of evidence suggest this conclusion.

2. Both $\delta^{18} \mathrm{O}$ and $\delta^{13} \mathrm{C}$ are impacted by light. In the field, light-induced increase in $\delta^{18} \mathrm{O}$ is masked by the temperature effect. $\delta^{13} \mathrm{C}$ may increase in the lateral corallite portion while simultaneously decreasing at the apex.

3. We did not observe a direct correlation between metabolism and isotopic data. This could be attributed to the systemic mixture of microstructures, for which the relative ratios varied in the measured samples.

4. Significant correlations between $\delta^{18} \mathrm{O}$ and $\delta^{13} \mathrm{C}$ were likely due to the kinetic deposition process of fibers (Juillet-Leclerc et al., 2009) and are not directly related to classical growth-rate measurements, density and linear extension. The strong relationships between oxygen and carbon isotopic fractionation, growth rate and light are much more complex than previously thought.

5. Light influence on $\mathrm{O}$ and $\mathrm{C}$ isotopic ratios is part of a vital effect, essentially inducing high colony variability and also horizontal variability on the surfaces of colonies in some species (McConnaughey, 1989). This could be due to the variable abundance of zooxanthellae, variable light incidence and/or the sampled morphological parts of corallites.

6. Variability of isotopic ratios is significant over the time only when measurements are performed along individual successive specimens, in this case corallites. 
These results provide evidence underlining the importance of the coral-algae symbiosis in coral-reef formation, especially concerning the strong and complex relationships between calcification and photosynthetic activity (Gattuso et al., 1999). Estimation of the relative importance of temperature and light effect on skeletal isotopic signatures will be investigated further in the future.

Vital effects are particularly complex in corals due to the impact of the zooxanthellate metabolism on the chemical features of the coral skeleton and the collective growth of a colony of multiple organisms. However, as we highlighted here, each specimen shows its own signature. Such a property is not a coral specificity, indeed inter- and intra-specimen variability of Mytilus edulis and Pecten maximus has still been stressed by Freitas et al. (2008).

Acknowledgements. The authors thank J. Lough and C. FerrierPagès for fruitful contributions, which significantly improved the quality of the manuscript. This work benefited greatly from the constructive comments of $\mathrm{E}$. Gladfelter and an anonymous reviewer and encouraging J. Bijma (associate Editor) comments. Additional thanks to Cecilia Garrec for English-language editing.

Edited by: J. Bijma

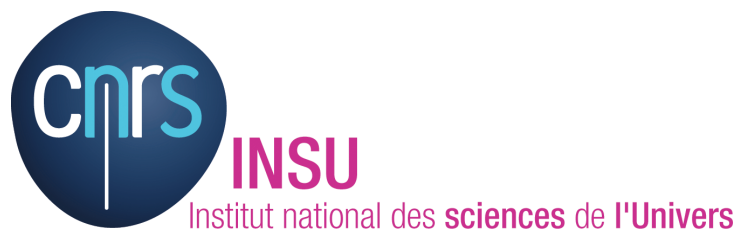

The publication of this article is financed by CNRS-INSU.

\section{References}

Barnes, D. J. and Lough, J. M.: On the nature and causes of density banding in massive coral skeletons, J. Exp. Mar .Biol. Ecol., 167, 91-108, 1993.

Cardinal, D., Hamelin, B., Bard, E., and Pätzold, J.: Sr/Ca, U/Ca and $\delta^{18} \mathrm{O}$ records in recent massive corals from Bermuda: relationships with sea surface temperature, Chem. Geol., 176, 213233, 2001.

Carricart-Ganivet, J. P.: Sea surface temperature and the growth of the West Atlantic reef-building coral Montastraea annularis, J. Exp. Mar .Biol. Ecol., 302, 249-260, 2004.

Chalker, B. E.: Simulating light-saturation curves for photosynthesis and calcification by reef-building coral, Mar. Biol., 63, 135$141,1981$.

Marshall, A. T. and Clode, P.: Calcification rate and the effect of temperatre in a zooxanthellate and an azooxanthellate scleractinian ref coral, Coral Reefs, 23, 218-224, 2004.

Cole, J. E., Fairbanks, R. G., and Shen, G. T.: Recent variability in the Southern Oscillation: Isotopic results from a Tarawa Atoll coral, Science, 260, 1790-1793, 1993.

Cruz-Piñon, G., Carricart-Ganivet, J. P., and Espinoza-Avalos, J.: Monthly skeletal extension rates of the hermatypic corals Mon- tastraea annularis and Montastraea faveolata: biological and environmental controls, Mar. Biol., 143, 491-500, 2003.

Cuif, J.-P. and Dauphin, Y.: Microstructural and physico-chemical characterisation of centres of calcification in septa of some Scleractinian corals, Pal. Zeit, 72, 257-270, 1998.

Cuif, J.-P., Dauphin, Y., Doucet, J., Salome, M., and Susini, J.: XANES mapping of organic sulphate in three Scleractinian coral skeletons, Geochim. Cosmochim. Acta, 67, 75-83, 2003.

Davies, P. S.: Short-term growth measurements of corals using an accurate buoyant weighing technique, Mar. Biol., 101, 389-395, 1989.

de Villiers, S., Nelson, B. K., and Chivas, A. R.: Biological controls on coral $\mathrm{Sr} / \mathrm{Ca}$ and $\delta^{18} \mathrm{O}$ reconstructions of sea surface temperature, Science, 269, 1247-1249, 1995.

Fairbanks, R. G. and Dodge, R. E.: Annual periodicity of the $18 \mathrm{O} / 16 \mathrm{O}$ and $13 \mathrm{C} / 12 \mathrm{C}$ ratios in the coral Montastrea annularis, Geochim. Cosmochim. Acta, 43, 1009-1020, 1979.

Dunbar, R. B., Wellington, G. M., Colgan, M. W., and Glynn, P. W.: Eastern Pacific sea surface temperature since 1600 A.D.: the $\delta^{18} \mathrm{O}$ record of climate variability in Galapagos corals, Paleoceanography, 9, 291-315, 1994.

Epstein, S., Buchsbaum, R., Lowenstam, H., and Urey, H. C.: Revised carbonate-water isotopic temperature scale, Bull. Geol. Soc. Am., 62, 417-425, 1953.

Erez, J.: Vital effect on stable-isotope composition seen in foraminifera and coral skeletons, Nature, 273, 199-202, 1978.

Felis, T., Pätzold, J., and Loya, Y.: Mean oxygen-isotope signatures in Porites sp. corals: inter-colony variability and correction for extension-rate effects, Coral Reefs, 22, 328-336, 2003.

Freitas, P. S., Clarke, L. J., Kennedy, H. A., and Richardson, C. A.: Inter- and intra-specimen variability masks reliable temperature control on shell $\mathrm{Mg} / \mathrm{Ca}$ ratios in laboratory- and field-cultured Mytilus edulis and Pecten maximus (bivalvia), Biogeosciences, 5, 1245-1258, 2008, http://www.biogeosciences.net/5/1245/2008/.

Furla, P., Galgani, I., Durand, I., and Allemand, D.: Sources and mechanisms of inorganic carbon transport for coral calcification and photosynthesis, J. Exp. Biol., 203, 3445-3457, 2000.

Gagan, M. K., Chivas, A. R., and Isdale, P. J.: High resolution isotopic records from corals using ocean temperature and massspawing chronometers, Earth Planet. Sci. Lett., 121, 549-558, 1994.

Gattuso, J.-P., Allemand, D., and Frankignoulle, M.: Photosynthesis and calcification at cellular, organismal and community levels in coral reefs: a review on interactions and control by carbonate chemistry, Amer. Zool., 39, 160-183, 1999.

Gladfelter, E. H.: Skeletal development in Acropora cervicornis: I. Patterns of calcium carbonate accretion in the axial corallite, Coral Reefs, 1, 45-51, 1982.

Gladfelter, E. H.: Skeletal development in Acropora cervicornis: II. Diel patterns of calcium carbonate accretion, Coral Reefs, 2, 91-100, 1983.

Gladfelter, E. H.: Skeletal development in Acropora cervicornis: III. A comparison of monthly rates of linear extension and calcium carbonate accretion measured over a year, Coral Reefs, 3 , 51-57, 1984

Gladfelter, E. H.: Skeletal development in Acropora palmata (Lamarck 1816): a scanning electron microscope (SEM) comparison demonstrating similar mechanisms of skeletal extension 
in axial versus encrusting growth, Coral Reefs, 26, 883-892, 2007.

Goreau, T. J.: Carbon metabolism in calcifying and photosynthetic organisms: theoritical models based on stable isotope data, Third international coral reef symposium, 395-401, 1977.

Goreau, T. J. and Goreau, N. I.: The physiology of skeleton formation in corals. II. Calcium deposition by hermatypic corals under various conditions on the reef, Biol. Bull. (Woods Hole), 118, 419-429, 1959.

Grottoli, A. G. and Wellington, G. M.: Effect of light and zooplankton on skeletal $\delta^{13} \mathrm{C}$ values in the eastern Pacific corals Pavona clavus and Pavona gigantean, Coral Reefs, 18, 29-41, 1999.

Grottoli, A. G.: Effect of light anf brine shrimp on skeletal $\delta^{13} \mathrm{C}$ in Hawaiian coral Porites compressa: a tank experiment, Geochim.. Cosmochim. Acta, 66, 1955-1967, 2002.

Guzman, H. M. and Thudope, A. W.: Seasonal variation in skeletal extension rate and stable isotopic $\left({ }^{13} \mathrm{C} /{ }^{12} \mathrm{C}\right.$ and $\left.{ }^{18} \mathrm{O} /{ }^{16} \mathrm{O}\right)$ composition in response to several environmental variables in the Caribbean reef coral Siderastrea sidereal, Mar. Ecol. Prog. Ser., 166, 109-118, 1998.

Heikoop, J. M., Dunn, J. J., Risk, M. J., McConnaughey, T. A., and Sandman, I. M.: Separation of kinetic and metabolic effect in carbon-13 records preserved in reef coral skeletons, Geochim. Cosmochim. Acta, 6, 975-987, 2000.

Highsmith, R. C.: Coral growth rates and environmental control of density banding, J. Exp. Mar. Biol. Ecol., 37, 105-125, 1979.

Jokiel, P. L,. Maragos, J. E., and Franzisket, L.: Coral growth: buoyant weight technique, in: Coral Reef: Research Methods, edited by: Stoddart, D. R. and Johannes, R. E., Unesco, Paris, 379-396, 1978.

Juillet-Leclerc, A. and Schmidt G.: A calibration of the oxygen isotope paleothermometer of coral aragonite from Porites, Geophys. Res. Lett., 28, 4135-4138, 2001.

Juillet-Leclerc, A., Reynaud, S., Rollion-Bard, C., Cuif , J.-P., Dauphin, Y., Blamart, D., Ferrier-Pagès, C., and Allemand, D.: Oxygen isotopic signature of the skeletal microstructures in cultured corals: identification of vital effects, Geochim. Cosmochim. Acta, 73, 5320-5332, 2009.

Linsley, B. K., Messier, R. G., and Dunbar, R. B.: Assessing between-colony oxygen isotope variability in the coral Porites lobata at Clipperton Atoll, Coral Reefs, 18, 13-27, 1999.

Lough, J. M. and Barnes, D. J.: Environmental control on growth of the massive coral Porites, Mar. Ecol. Prog. Ser., 245, 225-243, 2000.

Maier, C., Felis, T., Pätzold, J., and Bak, R. P. M.: Effect of skeletal growth and lack of species effects in the skeletal oxygen isotope climate signal within the coral genus Porites, Mar. Geol., 207, 193-208, 2004.

Marsh, J. A. J.: Primary productivity of reef building calcareous red algae, Ecol., 51, 255-263, 1970.

McConnaughey, T. A.: C-13 and O-18 isotopic desequilibrium in biological carbonates: I. Patterns, Geochim. Cosmochim. Acta, $53,151-162,1989 a$

McConnaughey, T. A.: C-13 and O-18 isotopic disequilibria in biological carbonates: II. In vitro simulation of kinetic isotope effects, Geochim. Cosmochim. Acta, 53, 163-171, 1989b.

McConnaughey, T. A., Burdett, J., Whelan, J. F., and Paull, C. K.: Carbon isotopes in biological carbonates: respiration and photosynthesis, Geochim. Cosmochim. Acta, 61, 611-622, 1997.
Meibom, A., Yurimoto, H., Cuif, J.-P., Domart-Coulon, I., Houlbrèque, F., Constantz B., Dauphin, B., Tambutté, E., Tambutté, S., Allemand, D., Wooden, J., and Dunbar, R.: Vital effect in coral skeletal composition display strict three-dimensional control, Geophys. Res. Lett., 33, L11608, doi:10.1029/2006GL025968, 2006.

Mendes, J.: Timing of skeletal band formation in Monstastrea annularis: relationship to environmental and endogeneous factors, Bull. Mar. Sci., 75, 423-437, 2004.

Muscatine, L. and Porter, J. W.: Reef corals: mutualistic symbiosis adapted to nutrient-poor environments, BioScience, 27, 454-459 1977.

Nothdurft, L. D. and Webb, G. E.: Microstructure of common reefbuilding coral genera Acropora, Pocillopora, Goniastrea, and Porites: constraints on spatial resolution in geochemical sampling, Facies, 53, 1-26, 2007.

Omata, T., Suzuki, A., Kawahat, H., and Okamoto, M.: Annual fluctuation in the stable carbon isotope ratio of coral skeletons: the relativeintensities of kinetic and metabolic isotope effect, Geochim. Cosmochim. Acta, 69, 3007-3016, 2005.

Quinn, T. M,. Taylor, F. W., and Crowley, T. J.: A 173 year stable isotope record from a tropical south Pacific coral, Quaternary Sci. Rev., 12, 407-418, 1993.

Raz-Bahat, M., Erez, J., and Rinkevich, B.: In vivo lightmicroscopic documentation for primary calcification processes in the hermatypic coral Stylophora pistillata, Cell. Tissue Res., 325, 361-368, doi:10.1007/s00441-006-0182-8, 2006.

Reynaud-Vaganay, S., Gattuso, J.-P., Cuif, J.-P., Jaubert, J., and Juillet-Leclerc, A.: A novel culture technique for scleractinian corals: application to investigate changes in skeletal $\delta^{18} \mathrm{O}$ as a function of temperature, Mar. Ecol. Prog. Ser., 180, 121-130, 1999.

Reynaud-Vaganay, S., Juillet-Leclerc, A., Gattuso, J.-P., and Jaubert, J.: Effect of light on skeletal $\delta^{13} \mathrm{C}$ and $\delta^{18} \mathrm{O}$ and interaction with photosynthesis, respiration and calcification in two zooxanthellate scleractinian corals, Paleogeogr. Paleocl., 175, 393-404, 2001.

Rollion-Bard, C., Chaussidon, M., and France-Lanord, C.: pH control on oxygen isotopic composition of symbiotic corals, Earth Planet. Sci. Lett., 215, 265-273, 2003.

Scoffin, T. P., Tudhope, A. W., and Brown, B. E.: Fluorescent and skeletal density banding in Porites lutea from Papua New Guinea and Indonesia, Coral Reefs, 7, 169-178, 1989.

Suzuki, A., Hibino, K., Iwase, A., and Kawahata, H.: Intercolony variability of skeletal oxygen and carbon isotope signatures of cultured Porites corals: temperature-controlled experiments, Geochim. Cosmochim. Acta, 69, 4453-4462, 2005.

Swart, P. K.: Carbon and oxygen isotope fractionation in scleractinian corals: a review, Earth-Sci. Rev., 19, 51-80, 1983.

Swart, P. K., Leder, J. J., Szmant, A., and Dodge, R. E.: The origins of variations in the isotopic record of scleractinian corals II. Carbon, Geochim. Cosmochim. Acta, 60, 2871-2886, 1996.

Tambutté, É., Allemand, D., Zoccola, D., Meibom, A., Lotto, S., Caminiti, N., and Tambutté, S.: Observations of the tissueskeleton interface in the Scleractinian coral Stylophora pistillata, Coral Reefs, 26, 517-529, 2007.

Urey, H. C., Lowenstam, H. A., Epstein, S., and McKinney, C. R. Measurements of paleotemperatures and temperatures of the Upper Cretaceous of England, Denmark, and the southern United 
States, Bull. Geol. Soc. Am., 62, 399-416, 1951.

Weber, J. N. and Woodhead, P. M. J.: Temperature dependence of Oxygen-18 concentration in reef coral carbonates, J. Geophys. Res., 7, 463-473, 1972.

Weber, J. N., Deines, P., Weber, P. H., and Baker, P. A.: Depth related changes in the $13 \mathrm{C} / 12 \mathrm{C}$ ratio in skeletal carbonate deposited by the Caribbean reef-frame building coral Monstatrea annularis: futher implications of a model for stable isotope fractionation by Scleractinian corals, Geochim. Cosmochim. Acta, 40, 31-39, 1976.
Weil, S. M., Buddemeier, R. W., Smith, S. V., and Kroopnick, P. M.: The stable isotopic composition of coral skeletons: control by environmental variables, Geochim. Cosmochim. Acta, 45, 1147 1153, 1981.

Wellington, G. M., Dunbar, R. B., and Merlen, G.: Calibration of stable oxygen isotope signatures in Galapagos corals, Paleoceanography, 11, 467-480, 1996. 